\title{
La no singularidad/monogamia en la unión marital de hecho... más que una pérdida emocional y afectiva
}

\author{
Non-singularity/monogamy in de facto marital union... \\ more than an emotional and affective loss
}

\section{Olga Cecilia Lopera Bonilla}

Magíster en Terapia Familiar

Abogada especialista en Derecho de Familia

Universidad Pontificia Bolivariana - Colombia.

olgaloperab@yahoo.com

\section{Resumen}

La singularidad/monogamia, entendida como el hecho de mantener una relación eróticoafectiva de convivencia singular ${ }^{1}$, excluye la multiplicidad de relaciones de la misma naturaleza en forma simultánea. Al ser acogida por las leyes religiosas y civiles, la singularidad/monogamia para las parejas unidas por matrimonio o unión marital de hecho se tornó en una obligación aunada a diversos derechos, entre ellos, los económicos.

1 Para una mayor comprensión de los lectores, se ha escrito el término "monogamia" en lugar de "singularidad" empleado en la legislación colombiana para los compañeros permanentes en la Unión marital de hecho, aunque el primero en estricto sentido de la definición de la RAE es el ("2. f. Régimen familiar que no admite la pluralidad de cónyuges") (Real Academia Española, 2020), siendo los cónyuges en la legislación colombiana las personas que han celebrado entre sí el contrato solemne de matrimonio. 
Este artículo se basa en la ley y la jurisprudencia de las altas cortes de Colombia para incitar a la reflexión sobre los efectos legales que implica la no singularidad/monogamia sobre la pareja estable y permanente, que en su opción de proyecto de vida, basado en el libre desarrollo de la personalidad, decide convivir en unión marital de hecho, la no singularidad/monogamia, además de conllevar una pérdida emocional y afectiva, implica la pérdida de los derechos personales y patrimoniales que la ley les otorga a quienes, sin estar casados, están unidos por lazos de afecto, solidaridad y ayuda mutua.

\section{Palabras clave}

Singularidad, monogamia; unión marital de hecho; pérdida de derechos.

\section{Abstract}

Singularity/monogamy, understood as the fact of maintaining an erotic-affective relationship of singular coexistence, simultaneously excludes the multiplicity of relationships of the same nature.

Being embraced by religious and civil laws, singularity/monogamy for couples united by marriage or de facto marital union, turned into an obligation tied to various rights, among them, economic rights.

This article is based on the law and the jurisprudence of the high courts of Colombia to encourage a reflection on the legal effects that non-singularity/monogamy implicates on the permanent and stable couple who, in their choice of life project based on the free development of personality, decide to live together in a de facto marital union, the non-singularity/monogamy; aside from entailing an emotional and affective loss, entails a loss of personal and patrimonial rights granted by law to those who, without being married, are united by ties of affection, solidarity, and mutual aid.

\section{Keywords}

Singularity, monogamy, de facto marital union, loss of rights.

\footnotetext{
Cómo citar este artículo:

Lopera Bonilla, O. (2021). La no singularidad/monogamia en la unión marital de hecho... más que una pérdida emocional y afectiva. Revista de la Facultad de Derecho y Ciencias Políticas, 51(135), pp. 423 - 441. doi: https://doi.org/10.18566/rfdcp.v51n135.a06
}

Recibido: 17 de septiembre de 2018

Aprobado: 12 de septiembre de 2019 


\section{Introducción}

El presente artículo pretende incitar en el lector la reflexión sobre la repercusión legal de la no singularidad en los derechos de las personas que se encuentran realizando un proyecto de vida permanente en pareja, ${ }^{2}$ mediante la unión marital de hecho y la forma en que la no singularidad puede ser usada como un argumento legal a favor propio o en contra de quien se asumía en calidad de compañero permanente, ya que, al no configurarse los elementos esenciales de esta figura jurídica, no se pueden pretender los derechos personales y patrimoniales que se desprenden de ella.

\section{Contexto histórico sobre la monogamia y la exclusividad de la pareja}

En los primeros grupos nómadas humanos no había un sentido de propiedad, vivían de la recolección de alimentos (incluida la carroña), la pesca y la caza. A finales del neolítico, cuando se aprendió a domesticar las plantas debieron asentarse para cosechar los frutos que producían los cultivos. En la apropiación de los animales y la tierra nació el derecho de propiedad (esto es mío/nuestro, no tuyo/de ellos).

El código de Hammurabi (data de 1750 A.C.), legislaba a los pueblos ubicados en región de Mesopotamia ubicada entre los ríos Tigris y Éufrates (Actualmente en territorio de Irak, Turquía y Siria), regulando el matrimonio como se podían obtener derechos legales como la permanencia a un grupo, la conservación del patrimonio familiar y la no dispersión de los bienes en beneficio de los hijos. La monogamia era obligatoria solo para la mujer, quien podía solicitar el divorcio si no aceptaba la poligamia de su marido, si ella era la infiel podía optar por ser esclava de su marido (y de sus mujeres) o excluida del grupo familiar.

Al querer transmitir lo que se posee, nació la necesidad en los hombres de asegurar la exclusividad sexual de la mujer para tener mayor certeza de cuáles eran sus hijos.

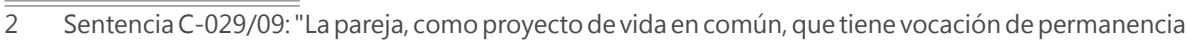
e implica asistencia recíproca y solidaridad entre sus integrantes, goza de protección constitucional, independientemente de si se trata de parejas heterosexuales o parejas homosexuales(...) (Corte Constitucional, 2009). 
Fue la primera forma de familia que tuvo por base condiciones sociales, y no las naturales; y fue, más que nada, el triunfo de la propiedad individual sobre el comunismo espontáneo primitivo. Preponderancia del hombre en la familia, y procreación de hijos que sólo pudieran ser de él y destinados a heredarle: tales fueron, franca y descaradamente proclamados por los griegos, los únicos móviles de la monogamia. (Engels, 1980) (Pgs 72-73)

Cuando Justiano continuó con la obra de Constantino para compilar las normas jurídicas romanas ${ }^{3}$ en el Corpus Iuris Civilis ${ }^{4}$, dentro de las formas de unión de las parejas quedó consignada la existencia del concubinato, que se configuraba cuando no existía la affectio maritalis ${ }^{5}$, es decir, no se tenía la intensión de casarse, distinguiéndose de una simple relación sexual por la estabilidad del vínculo y la obligación de la singularidad (al igual que en el matrimonio). A medida que el imperio se expandió, sus leyes abarcaron todos los territorios conquistados, entre ellos la península ibérica. Los habitantes del imperio podían optar entre el matrimonio o el concubinato, el cual "se trató de una relación reconocida socialmente. Fue una relación sexual lícita siempre que fuera monogámica y permanente, con la recíproca intención de estar unidos” (Marín, 2005, p. 242).

Los hombres sentían la infidelidad como un agravio o una ofensa, solo en la medida en que podían considerar herederos de sus bienes a quienes, en realidad, no lo eran. (Veiga, 2016, p. 161)

El 27 de febrero del año 380 D.C., durante el reinado de Teodosio, emperador romano de Oriente, se expidió el decreto Cunctos populos (Edicto de Tesalónica), el cual declaró al cristianismo religión del Estado y permitió perseguir a quienes profesaran otra fe (herejes y judíos) o practicaran los ritos de sus creencias, castigando con la pérdida de derechos a los que no se acogieran a las normas cristianas. El matrimonio entre cristianos y judíos era considerando adulterio.

\footnotetext{
3 "... el Derecho Romano es aquel ordenamiento jurídico que rigió al pueblo romano desde el siglo VIII a.C. hasta el siglo VI d.C (754 a.C. al 565 d.C), siendo el Corpus Iuris Civilis (C.I.C.) el gran monumento jurídico, mandado compilar por Justiniano, donde se recoge todo el saber jurídico y, en consecuencia, es un pilar decisivo en la Historia jurídica mundial". (Baquero, 2012)

4 "El Corpus Iuris Civilis es una obra que vio la luz por primera vez entre los años 527 y 565, cuando Justiniano, en su afán de formalizar el ordenamiento jurídico del Imperio, llevó a cabo la mayor recopilación del Derecho romano de la época. Esta acción fue el resultado de un proceso que venía desarrollándose desde el gobierno de Constantino (306 - 337 d. C.)" (Campillo \& Restrepo, 2016)

5 Desde el punto de vista del matrimonio es el "acuerdo de voluntades por el que los contrayentes asienten en considerarse marido y mujer". (Valencia, 1986) (pg. 170)
} 
La ley introducía novedades en materia de matrimonio y adulterio y así lo reconocieron los compiladores del Codex Theodosianus al incluirla en dos libros distintos, el III y el IX, bajo las rúbricas de nuptiis y ad legem Iuliam de adulteriis respectivamente. En el primer caso, formulaba por primera vez la disparitas cultus como impedimento matrimonial ${ }^{6}$; en el segundo, ampliaba las prácticas susceptibles de ser englobadas en el crimen de adulterium y permitía, para este caso concreto, el ius accusandi a todo el que quisiera ejercerlo, al margen de la relación familiar ${ }^{7}$. (Escribano, 2008, p. 33)

Ya que la posibilidad de realizar la acusación de adulterio se había ampliado a cualquier persona fuera de la relación familiar ${ }^{8} \mathrm{e}$ implicaba la pena de muerte tanto para hombres como para mujeres, fue un instrumento de terror para hacer cumplir la ley y se utilizó como arma política contra los enemigos. Solo era legítimo el matrimonio celebrado entre cristianos si solo practicaban ritos de esa fe.

En el año 395 d.C. el emperador Teodosio I dividió el Imperio Romano entre sus dos hijos: Occidente para Honorio (cuya capital era Mediolanum -actual Milán- integrado por las provincias de Hispania, Italia, Galia, Britania, Mauritania y África) y Oriente para Arcadio (imperio Bizantino cuya capital era Constantinopla, actualmente Estambul, incluía la Península Balcánica, Asia Menor, Siria, Palestina y Egipto) e impuso el cristianismo como la religión oficial en ambos. Aún después de la caída de estos (el primero en el año 476 y el segundo en el 1453), continuó la influencia del cristianismo en las normas de los nuevos reinos europeos.

Al finalizar el siglo v, del antiguo Imperio de Occidente no quedaba sino un conjunto de reinos autónomos, generalmente hostiles entre sí y empeñados en mantener su supremacía. Este vacío de poder fue propicio para que

\footnotetext{
6 En la legislación constantiniana era impedimento la diferencia de rango, status y ciudadanía.

7 El marido debía divorciarse de la adúltera o incurría en la acusación de lenocinium (mientras continuara casada no se le podía castigar) y luego acusarla (podía hacerlo aún si solo sospechaba de ella). La adúltera se asimilaba a una prostituta -la prostitución y la magia eran causales de repudio-.

En términos legales estrictos, era la mujer la que estaba sujeta a la incriminación por adulterio. En el caso de los hombres, casados o célibes, sólo podían ser acusados cuando la mujer con la hubieran mantenido relaciones fuera una mater familias, es decir, una notae auctoritatis femina, caracterizada por sus boni mores. En los demás casos, era reprobable moralmente, pero no perseguible legalmente. Puesto que la mujer no tenía derecho alguno sobre el marido, los hombres desposados no eran incriminables como adúlteros, aunque hubiesen tenido relaciones con mujeres de boni mores, si éstas no estaban aún casadas. (Escribano, 2008) (pg 43)

8 En la anterior legislación era un derecho reservado al marido y al padre de la adúltera (tenían 60 días para denunciarla).
} 
el obispo de Roma se convirtiera en la única autoridad indiscutida en los ámbitos religioso, cultural y político. (Bejarano, 2016)

Aunque al llegar a las tierras del continente americano en 1492, los Reyes católicos -título dado por el papa Alejandro VI (Rodrigo de Borgia) a Fernando II de Aragón e Isabel I de Castilla- y encontrar que sus habitantes se regían por normas y costumbres que les eran propias, impusieron la religión, idioma y legislación españolas, las cuales estaban permeadas por la legislación romana.

El Nuevo Mundo fue descubierto y conquistado cuando en Europa comenzaban a consolidarse las monarquías absolutas, y la relación IglesiaEstado se fortalecía dando pie a las grandes concesiones eclesiásticas a las coronas europeas. Como ejemplo, las Bulas Alejandrinas ${ }^{9}$, junto con las otorgadas por Julio II, establecieron las bases para la evangelización de las Indias Occidentales y, con ello, la transformación religiosa, política, económica y social del mundo entero. (...) (Bejarano, 2016)

Para facilitar la conquista y la hispanización, en 1514 en respuesta a la propuesta del obispo de Concepción, el Rey Fernando expidió una Real Cédula permitiendo inicialmente en las Antillas el matrimonio entre españoles e indígenas suprimiendo todas las prohibiciones que había al respecto ${ }^{10}$. (Rodríguez, 2015).

En la época precolombina e inicios de la conquista española, el imperio Incaico (1438-1533) había consolidado el Tawantinsuyo "las cuatro partes del mundo en una” que abarcaba desde el norte de Argentina hasta el sur de Colombia y desde el océano Pacífico hasta la Amazonía. Entre los Pacajes de la región andina era usual el Servinacuy y el Tincunacuy ${ }^{11}$ o "matrimonio de prueba” (Cobo 1963), no siendo la castidad de la mujer un aliciente, ni su maternidad un impedimento para el matrimonio. Por el contrario, al menos entre la gente común era un incentivo. En cambio se tomaba muy en cuenta sus bienes y habilidades. (Arapa, 2018)

Con el ánimo de colonizar las nuevas tierras y extraer riquezas, al sur del continente llegaron hombres sin sus esposas y familias, surgiendo una nueva

$9 \quad$ Grupo de cartas pontificias otorgadas por Alejandro VI entre mayo y septiembre de 1493

10 (Indiferente 419.1.5.f 268)

11 "McLean y Estenos considera la palabra servinacuy como un término español quechuizado que indica servicio mutuo, mientras que tincunacuspa vendría del verbo tincunacuy que expresa acción y efecto de dos personas que viven íntimamente". (Arapa, 2018) (pg 38) 
raza mixta por la proliferación tanto de matrimonios como de uniones en concubinato con las nativas americanas. Debido al arduo trabajo en las minas y las nuevas enfermedades que introdujeron los europeos la población originaria y mestiza se vio diezmada. Al no estar permitida la esclavitud de los indios que trabajaban en las encomiendas salvo en los casos de rebelión, los virreyes y encomenderos iniciaron el comercio de esclavos que provenían de África.

(...) uno de los motivos que impulsaron el comercio esclavista en la Nueva España fue la crisis demográfica que inició hacia finales de la primera mitad del siglo XVI, cuando se desataron pandemias en la Colonia que generaron la muerte de miles de indígenas en todo el territorio, haciendo que a principios del siglo XVII el número de pobladores originarios se redujera drásticamente, lo cual significó para los españoles de la Colonia escases en las fuentes de fuerza de trabajo, falta que fue compensada con la llegada de esclavos africanos. (Secretaría de Cultura Gobierno de México, 2019)

El mestizaje en América no solo fue biológico, confluyeron en este lugar las costumbres y leyes españolas con las de los pueblos originarios, predominando las primeras, lo que no implicó que se extinguirse completamente el espíritu de las segundas, el cual permeó la cultura mixta de los habitantes de estas tierras.

\section{El matrimonio, el concubinato y la unión marital de hecho en Colombia}

Entre las leyes españolas que rigieron el nuevo mundo se encontraban "Las siete partidas” de Alfonso X el Sabio, la cual regulaba asuntos relativos a las personas y poniendo a la mujer bajo la tutela permanente del varón (Partida VII. Título XXXIII, Ley XII). A partir de la independencia, los nuevos gobiernos americanos se vieron en la necesidad de crear leyes que reemplazaran 0 dieran coherencia y orden a las ya existentes; es así que mediante la Ley 84 de 1873 (Diario Oficial No. 2.867 de 31 de mayo de 1873) se adaptó el Código civil chileno de 1855, redactado por el venezolano don Andrés Bello para los Estados Unidos de Colombia, en el cual se conjugaban los antecedentes normativos de la legislación francesa.

Hasta la promulgación de la Ley 28 de 1932, el Código civil colombiano (Ley 57 de 1887) en su artículo 177 original establecía que "La potestad patrimonial 
es el conjunto de derechos que las leyes conceden al marido sobre la persona y bienes de la mujer" (Congreso de la República, 1887), siendo el matrimonio el único medio legítimo para constituir una familia, por lo cual la mujer no casada y sus hijos quedaban al margen de la Ley.

Sin importar la duración del "concubinato" o "unión libre” las mujeres no tenían derechos patrimoniales sobre los bienes de su pareja, a su vez, los hijos naturales (reconocidos por el padre) heredaban junto con todos los demás hijos naturales que hubiere procreado un hombre, una quinta parte de sus bienes. El derecho de representación era exclusivo para los parientes legítimos, como lo consagraba el código civil, en su artículo 1045:

Los hijos legítimos excluyen a todos los otros herederos, excepto a los hijos naturales, cuando el finado haya dejado legítimos y naturales; la herencia se dividirá en cinco partes: cuatro para los hijos legítimos exclusivamente y una para todos los naturales (...) (Ley 57 de 1887).

La Ley 45 de 1936 -sobre reformas civiles (filiación natural), en el artículo 18 se les concedió a los hijos naturales una mayor porción de la herencia, pero no el mismo derecho que a los hijos legítimos. La Ley 29 de 1982 consagró igualdad de derechos herenciales a los hijos legítimos, extramatrimoniales y adoptivos.

\section{De la unión libre a la unión marital de hecho}

Hasta principios de la última década del siglo XX, la legislación colombiana continuaba aferrada a una normativa del siglo IV que perpetuaba la inequidad entre las parejas en matrimonio o en concubinato. En su artículo 113, el Código civil colombiano define el matrimonio como "un contrato solemne por el cual un hombre y una mujer ${ }^{12}$ se unen con el fin de vivir juntos, de procrear y de auxiliarse mutuamente” (Congreso de la República, 1887). Con la expedición de la Ley 54 de 1990, modificada por la Ley 979 de 2005) en el país la "unión libre” se consagró como unión marital de hecho - conservándose la libertad de inicio y terminación del vínculo sin los requisitos exigidos para el contrato solemne del matrimonio-, se les otorgó el nombre de compañeros

12 En Sentencia C-577, de 2011, la Corte Constitucional ordenó se le dieran los mismos efectos del matrimonio a las parejas homosexuales que se casen civilmente.

La Corte Constitucional estableció mediante (la Sentencia SU 214, de 2016, que los matrimonios civiles celebrados entre parejas del mismo sexo, con posterioridad al veinte (20) de junio de 2013, gozan de plena validez jurídica. 
permanentes a quienes conviven sin casarse, se establecieron los derechos y obligaciones entre ellos y hacia los hijos, los mecanismos para demostrar la existencia y validez de esa figura jurídica, la presunción y efectos de la sociedad patrimonial, entre otros.

La Ley 54 de 1990 en su artículo primero establece:

A partir de la vigencia de la presente Ley y para todos los efectos civiles, se denomina unión marital de hecho, la formada entre un hombre y una mujer, que sin estar casados, hacen una comunidad de vida permanente y singular. Igualmente, y para todos los efectos civiles, se denominan compañero y compañera permanente, al hombre y la mujer que forman parte de la unión marital de hecho ${ }^{13}$. (Ley 54, 1990)

Esta Ley representó un gran avance hacia la justicia y equidad que eran necesarias para las familias constituidas por fuera del matrimonio, que fueron reconocidas en 1991 en el artículo 42 de la Constitución Política de Colombia: "La familia es el núcleo fundamental de la sociedad. Se constituye por vínculos naturales o jurídicos, por la decisión libre de un hombre y una mujer de contraer matrimonio o por la voluntad responsable de conformarla (...)” ${ }^{14}$. (Constitución Política, 1991).

Esa voluntad responsable conlleva ciertos presupuestos que la diferencian de otras formas de relacionarse en pareja, como lo manifiesta la jurisprudencia de las altas cortes, entre ellas la Sentencia 239 de 2001 de la Corte Suprema de Justicia:

(...) La configuración de la unión marital de hecho, presupone (...) un conjunto de elementos fácticos objetivos como la convivencia, la ayuda y el socorro mutuos, las relaciones sexuales y la permanencia, y subjetivos otros, como el ánimo mutuo de pertenencia, de unidad y la affectio maritales ${ }^{15}(\ldots)$. (2001)

13 Declarada exequible por la Corte Constitucional mediante la Sentencia C-075 de 2007, magistrado ponente, Rodrigo Escobar Gil, "en el entendido que el régimen de protección en ella contenido se aplica también a las parejas homosexuales" (Sentencia C-075, 2007). Ver Sentencia C-193 de 20 de abril de 2016, magistrado ponente, Luis Ernesto Vargas Silva.

14 Sentencia C-577, de 2011y Sentencia SU 214/16 (ver pie de página número 12)

15 Posición reiterada en fallos de 27 de julio de 2010, expediente 00558, y de 18 de diciembre de 2012, expediente 00313, SC15173-2016 de 24 de octubre de 2016, exp. 2011-00069-01 y otros. 
Posteriormente esa misma corporación en Sentencia SC 4360 de 2018, enuncia los supuestos necesarios para que sea declarada judicialmente la existencia de una unión marital de hecho:

5. En ese entendido, para la prosperidad de la acción que procure la declaración de unión marital de hecho y consecuente sociedad patrimonial entre compañeros permanentes de parejas del mismo sexo, resulta imperativo que, conforme lo exigen las leyes 54 de 1990 y 979 de 2005, se satisfagan los requisitos de comunidad de vida, permanencia y singularidad, de los cuales se ha dicho que: (i) la comunidad de vida refiere a esa exteriorización de la voluntad de los integrantes de conformar una familia, manifestado en la convivencia, brindándose respeto, socorro y ayuda mutua, compartiendo metas y asuntos esenciales de la vida, “(...) esa comunidad de vida debe ser firme, constante y estable, pues lo que el legislador pretende con esa exigencia es relevar que la institución familiar tiene, básicamente, propósitos de durabilidad, de estabilidad y de trascendencia”" ${ }^{16}$, la cual se encuentra integrada por unos elementos “(...) fácticos objetivos, como la convivencia, la ayuda y el socorro mutuos, las relaciones sexuales y la permanencia, y subjetivos otros, como el ánimo mutuo de pertenencia, de unidad y la affectio maritalis $(. . .)^{17}$;;(ii) la permanencia, que refiere a la forma de vida en que una pareja idónea comparte voluntaria y maritalmente, guiada por un criterio de estabilidad y permanencia, en contraposición de las relaciones esporádicas, temporales u ocasionales y; (iii) la singularidad indica que únicamente puede unir a dos personas idóneas, "atañe con que sea solo esa, sin que exista otra de la misma especie, cuestión que impide sostener que la Ley colombiana dejó sueltas las amarras para que afloraran en abundancia uniones maritales de hecho ${ }^{18}$ ". (Corte Suprema de Justicia, 2018)

En la unión marital de hecho la singularidad de la pareja es un elemento fundamental, mientras que en el contrato matrimonial es un efecto personal, como se leen en la Sentencia C-727 de 2015: “(...) entre los principales se encuentran la obligación de fidelidad, la obligación de socorro y ayuda mutua, de convivencia y el cambio del estado civil de soltero a casado" (Decreto 1260, $1970)^{19}$, por ello una persona puede simultáneamente estar casada y convivir en

16 CSJ SC de 10 de abril de 2007, Exp. 20010045101.

17 CSJ. Civil. Sentencia-239 de 12 de diciembre de 2001. Reiterada en fallos de 27 de julio de 2010, expediente 00558, y del 18 de diciembre de 2012, expediente 00313, SC15173-2016 de 24 de octubre de 2016, exp. 2011-00069-01, entre otros.

18 CSJ SC del 20 de septiembre de 2000, exp. 6117.

19 La Ley 25 de 1992 ordena que todos los matrimonios celebrados en Colombia o por nacionales colombianos en el exterior, sean registrados en el registro civil de matrimonio, ya que es el único 
forma permanente con otra persona sin que esa situación afecte la existencia del contrato matrimonial, por el contrario la no singularidad desvirtúa la unión marital de hecho.

\section{Consecuencias de la no singularidad en la unión marital de hecho}

En la Sentencia 6117 de la Corte Suprema de Justicia, Sala de Casación Civil y Agraria, del 20 de septiembre de 2000, indica sobre la unión marital de hecho que "(..) no es posible que coexistan varias uniones respecto de la misma persona”.

“... la diversidad de uniones maritales puede darse respecto del hombre 0 de la mujer; pero, van en contra del propósito de la ley que se inspiró en el principio de la monogamia. Esa pluralidad no produce efectos civiles. (Corte Suprema de Justicia, 2000)

Posteriormente esa misma corporación en Sala de Casación Civil, expresó en Sentencia SC 4361-2018:

El artículo $1{ }^{\circ}$ de la Ley 54 de 1990 establece, que hay unión marital de hecho entre quienes, sin estar casados, "hacen una comunidad de vida permanente y singular"; queda implícito, que no habrá lugar a esta si alguno de los pretensos compañeros tiene otra relación paralela de similares características, pues no se cumpliría el presupuesto de singularidad que expresamente establece la ley, en la medida en que resulta inadmisible pregonar la existencia de comunidad de vida con más de una persona con capacidad suficiente para generar de ambas los efectos jurídicos que, en protección a la institución familiar, se reconocen, tanto al matrimonio como a la unión marital de hecho.

(...) No es el conocimiento o no que pueda tener la pareja de la existencia de otras relaciones simultaneas de su compañero lo que afecta la existencia de la unión, sino las condiciones en que aquellas se desarrollen, pues no pueden coexistir varias uniones maritales capaces de generar efectos económicos,

documento válido para probar su existencia. La Ley 1395 de 2010 permite que la inscripción del matrimonio se realice en cualquier notaría, registraduría auxiliar, especial y municipal del país, o consulado de Colombia en el exterior. 
aun cuando pueden presentarse episodios de infidelidad. (Corte Suprema de Justicia, 2018)

Al respecto dice la Corte Suprema de Justicia en Sentencia SC15173-2016:

(...) la infidelidad generalmente conduce a la ruptura de la unión marital, pues constituye una afrenta a la lealtad y al respeto recíproco debido. Empero, pese a conocerse la falta, al pervivir la relación de pareja, se entiende que el agraviado la perdonó o toleró, sin afectar la comunidad de vida, pues como se indicó, con esa finalidad se requiere la separación física y definitiva, bastando para el efecto que “(...) uno de los compañeros, o ambos, decidan darla por terminada (...)”. (Corte Suprema de Justicia, 2016)

En el caso de las personas que continúan casadas y que sin haber cumplido el trámite del divorcio o de la cesación de efectos civiles de matrimonio religioso, conviven en forma permanente con otra pareja, para que surja la unión marital de hecho se requerirá que los cónyuges estén separados de cuerpos (no convivan), como aclara la Corte Suprema de Justicia en Sentencia 2008-00084 del 5 de agosto de 2013:

No hay campo para compromisos alternos de los compañeros permanentes con terceras personas, toda vez que se requiere una dedicación exclusiva al hogar que se conforma por los hechos, ya que la pluralidad desvirtúa el concepto de unidad familiar que presuponen esta clase de vínculos.

(...) En otras palabras, no se permite la multiplicidad de uniones maritales, ni mucho menos la coexistencia de una sola con un vínculo matrimonial en el que no estén separados de cuerpos los cónyuges. Sin embargo, cuando hay claridad sobre la presencia de un nexo doméstico de hecho, los simples actos de infidelidad no logran desvirtuarlo, ni se constituyen en causal de disolución del mismo, que solo se da con la separación efectiva, pues, como toda relación de pareja, no le es ajeno el perdón y la reconciliación”. (Corte Suprema de Justicia, 2013)

En los eventos en los cuales se ha(n) presentado episodio(s) de infidelidad, sea emocional o física, el vínculo de los compañeros permanentes continuará como tal hasta que uno de ellos decida separarse ya que la terminación del vínculo es una potestad libre que no requiere invocar una causal. Es entonces la simultaneidad de "uniones maritales”, mas no la infidelidad (entendida como una relación erótico afectiva no permanente con una tercera persona diferente a la pareja) lo que impide se constituya la unión marital de hecho. 


\section{La no singularidad y la pérdida de los derechos de los compañeros permanentes surgidos de la unión marital de hecho}

Cumpliéndose los requisitos del artículo 2 de la Ley 54 de 1990 º, en aras de facilitar la demostración de la existencia de la unión marital de hecho y sus efectos patrimoniales entre compañeros permanentes, la Ley 979 de 2005 la modifica parcialmente permitiendo que se declare por cualquiera de los mecanismos consagrados en su artículo segundo: 1) Por escritura pública ante notario por mutuo consentimiento de los compañeros permanentes; 2) por acta de conciliación suscrita por los compañeros permanentes, en centro legalmente constituido; y 3) por sentencia judicial, mediante los medios ordinarios de prueba consagrados en el Código de procedimiento civil, con conocimiento de los jueces de familia de primera instancia. (Ley 979, 2005).

Para entrar a liquidar la sociedad patrimonial hay que tener en cuenta que la Ley 54 de 1990 indica cuáles bienes hacen o no parte de ella ${ }^{21}$ y que adicionalmente consagra un límite de tiempo para iniciar las acciones de disolución y liquidación, por lo que las mismas prescriben, según el Artículo 8, “ (...) en un año, a partir de la separación física y definitiva de los compañeros, del matrimonio con terceros o de la muerte de uno o ambos compañeros”(Congreso de la República, 1990, por lo que pasado ese año los activos y pasivos quedan en cabeza de quien figura como titular de los mismos.

No existiendo ni la singularidad ni la exclusividad en la pluralidad de "uniones maritales de hecho" (homosexual o heterosexual) ${ }^{22}$, el o la no monógamo(a) está en concubinato con sus diferentes parejas, lo que implica que en esas relaciones los derechos patrimoniales se regirán por lo establecido para las

20 La Corte Constitucional, mediante Sentencia C-700-13, declaró inexequible la parte de la norma que exigía que la sociedad conyugal estuviera liquidada y que esto se hubiese hecho 'por lo menos un año' antes de que se iniciara la unión marital de hecho, por lo cual solo se requiere que esté disuelta por cualquiera de los mecanismos para ello.

21 Artículo 3 de la Ley 54 de 1990: "No formarán parte del haber de la sociedad los bienes adquiridos en virtud de donación, herencia o legado, ni los que se hubieren adquirido antes de iniciar la unión marital de hecho, pero sí lo serán los réditos, rentas, frutos o mayor valor que produzcan estos bienes durante la unión marital de hecho" (Congreso de Colombia, 1990).

22 (Sentencia C-174, 1996). Los derechos y deberes que comporta el estado civil deben ser fijados, entre otros factores, de conformidad "con la evolución social", de modo que el paso del tiempo podría conducir a "avanzar hacia la igualdad, dentro de lo posible, entre el tratamiento jurídico de los cónyuges y de los compañeros permanentes". 
sociedades de hecho, de acuerdo a lo expresado la Corte Constitucional en Sentencia C-114 de 1996:

(...) Es claro, en consecuencia, que si uno de los compañeros permanentes, o uno de sus herederos, no reúne los presupuestos señalados en la Ley para demandar el reconocimiento de la existencia y disolución de la sociedad patrimonial regulada por la citada Ley 54, podrá demandar para que se declare la existencia y disolución de la sociedad de hecho entre concubinos. (Corte Constitucional, 1996)

Posteriormente, en la Sentencia C-901 de 2003, la Corte Constitucional expresó: “...No puede decirse que tal capital es de exclusiva propiedad del concubino, sino de ambos, pues su formación se hizo dentro del estado de concubinato y con ocasión del mismo”.

Cuando no hay singularidad en la unión marital de hecho la sociedad patrimonial se torna en un hecho incierto y ambiguo, ya que su inexistencia o existencia podrá ser alegada por cualquiera de los "supuestos compañeros permanentes” según su conveniencia, incluso en detrimento del otro, para quien comprobar cuándo se rompió la singularidad, adquiere una gran relevancia e implica la defensa de los derechos que quien mantuvo el pacto de exclusividad creía tener por estar de buena fe en una relación que en algún momento dejó de ser una unión marital de hecho para convertirse en concubinato y la sociedad patrimonial en sociedad de hecho.

Además de la sociedad patrimonial, la unión marital de hecho otorga a los compañeros permanentes una serie de derechos patrimoniales y personales, los cuales también se pueden perder por la no singularidad. En estos casos será el ente judicial competente, quien basado en las pruebas presentadas por las partes, decrete la existencia o no de la unión marital de hecho, hasta qué momento existió y si los miembros de la pareja heterosexual u homosexual ${ }^{23}$ conservan o les son otorgados cuáles de los siguientes derechos: La afiliación a salud como beneficiario de compañero/a permanente (artículo 163 de la Ley 100 de 1993 (Sentencia C-521, 2007), (Sentencia C-075, 2007), (Sentencia C-811, 2007)-; la pensión de sobrevivientes ${ }^{24}$ (artículos 47 y 74 de la Ley

Sentencia C-029 de 2009 y Sentencia SU214/16

Sentencia C-336 de 2008. Las parejas permanentes conformadas por personas del mismo sexo también son beneficiarias de la pensión de sobrevivientes siempre y cuando acrediten su condición en la misma forma en la que lo hacen las parejas heterosexuales, esto es, mediante la expresión, ante un notario, de la voluntad de conformar una pareja singular y permanente, tal como fue indicado en la Sentencia C-521 de 2007. 
100 de 1993, modificados por la Ley 797 de 2003), (Sentencia C-521, 2007), (Sentencia T-1241, 2008), (Sentencia T-932, 2008), (Sentencia C-336, 2008)-; el deber-derecho de alimentos (Artículo 411 del Código Civil (Sentencia C-1033 de 2002-); la tipificación del delito de inasistencia alimentaria (parágrafo $1 .^{\circ}$ del Artículo $1 .^{\circ}$ de la Ley 1181 de 2007), (Sentencia C-978, 2008); la porción conyugal (Sentencia C-283, 2011); y la herencia para compañeros permanentes (Sentencia C-238, 2012).

Así mismo, se deben analizar los derechos al patrimonio de familia inembargable y la afectación de bienes inmuebles a vivienda familiar, el subsidio familiar para vivienda, los derechos migratorios, la garantía de no incriminación en materia penal, la circunstancias de agravación punitiva, las indemnizaciones de SOAT por muerte en accidentes de tránsito, la prohibición consagrada en el Artículo 33 (Constitución Política, 1991) a obligar a declarar contra sí mismo o contra el cónyuge, compañero permanente "o parientes dentro del cuarto grado de consanguinidad, segundo de afinidad o primero civil”, en el caso de que haya un proceso o investigación en curso; los deberes relacionados con el acceso y ejercicio de la función pública y la celebración de contratos estatales - régimen de incompatibilidades e inhabilidades basadas en el parentesco por afinidad-, la adquisición y la pérdida de la nacionalidad, las medidas administrativas de protección a la familia, y los destinatarios de las medidas para la prevención del desplazamiento forzado ${ }^{25}$

En este orden de ideas, debe prestarse especial atención a los efectos que esa declaratoria tiene en los procesos de adopción en curso del hijo de la pareja, caso en el cual prima el derecho del niño, la niña o el adolescente, a que se le otorgue una protección especial en situaciones de debilidad manifiesta, como el abandono (Sentencia C-477, 1999).

\section{Reflexión}

Ya que para los compañeros permanentes la legislación no contempla la posibilidad de solicitar alimentos sanción en los casos de multiplicidad de relaciones permanentes, ¿Quien conservó el pacto de singularidad puede demandar a quien lo rompió por la indemnización de los perjuicios económicos

$\overline{25}$ Sentencia C-029 de 2009. Unifica el régimen normativo en estas materias en cuanto deben incluir a los integrantes de las parejas del mismo sexo. 
y pérdida de derechos personales derivados de la no existencia de la unión marital de hecho?

\section{Conclusión}

Por todo lo anteriormente expuesto, se considera que la no singularidad en la unión marital de hecho puede conllevar para los compañeros permanentes más que una pérdida emocional y afectiva.

Dado que en nuestro actual régimen legislativo (que puede considerarse mixto), entretanto el Congreso de la República no modifique o derogue una norma ni la Corte Constitucional la encuentre Inexequible (parcial o condicionadamente), la norma continúa vigente y debe ser interpretada tomando en cuenta todos los elementos que la componen.

Es importante tener claridad y unidad de criterios en los diversos casos en que se presentan a consideración de los operadores jurídicos, abogados, jueces y magistrados las consecuencias de la no singularidad en la unión marital de hecho, ya que tanto la legislación vigente como la jurisprudencia son reiterativas al consagrar la singularidad como un requisito esencial de su existencia, de lo cual dependen los derechos y obligaciones que esta les otorga a los compañeros permanentes o en su defecto, a los concubinos.

Será finalmente el órgano judicial competente en cada caso quien, con base en la Ley, la jurisprudencia y los hechos planteados por las partes en el respectivo proceso, determine quiénes y hasta qué momento tienen los derechos que la unión marital de hecho les otorga a los compañeros permanentes.

\section{Referencias}

Alonso, M. L. (1997). El consentimiento para el matrimonio de los miembros de la Familia Real (Sobre la vigencia de la Pragmótica de Carlos III de 1776). (U. C. Madrid, Ed.) Cuadernos de Historia del Derecho, n 0 4,61. Retrieved from file:///C:/Users/senoritas/Downloads/21337-Texto\%20del\%20art\%C3\%ADcu lo-21377-1-10-20110603.PDF

Arapa, S. J. (2018). Matrimonio y sexualidad en la historia Cultural de los Inkas: Hacia una aproximación de las normas Inkas en materia sexual y su relación con la economía e ideas religiosas sobre la producción de la Pacha. Retrieved Enero 21, 2021, from http://repositorio.unsa.edu.pe/bitstream/handle/UNSA/5929/CHDarvisj. pdf? sequence $=1$ \&isAllowed $=y$ 
Bejarano, M. d. (2016). Las Bulas Alejandrinas: Detonates de la evangelización en el Nuevo Mundo. (6. 2.-2. Revista de El Colegio de San Luis, Ed.) Retrieved Enero 22, 2021, from http://www.scielo.org.mx/scielo.php?script=sci_artt

Cáceres, R. (2008). Las conexiones entre Centroamérica y África. Retrieved Enero 20, 2021, from Del olvido a la memoria. África en tiempos de la esclavitud. (p 11-17): https://unesdoc.unesco.org/ark:/48223/pf0000183851

Congreso de la República. (1887, 26 de mayo). Ley 57, Código Civil Colombiano. Diario Oficial No. 7.019 del 20 de abril de 1887. Recuperado de https://www.icbf.gov.co/ cargues/avance/docs/ley_0057_1887.htm

Congreso de la República de Colombia. (1936, 5 de marzo). Ley 45, Sobre reformas civiles (filiación natural). Diario Oficial No. 23.147 de 30 de marzo de 1936. Recuperado de https://www.icbf.gov.co/cargues/avance/docs/ley_0045_1936.htm

Congreso de Colombia. (1982, 24 de febrero). Ley 29, Por la cual se otorga igualdad de derechos herenciales a los hijos legítimos, extramatrimoniales y adoptivos y se hacen los correspondientes ajustes a los diversos órdenes hereditarios ". Diario Oficial No. 35.961 (D. Recuperado de https://www.icbf.gov.co/cargues/avance/ docs/ley_0029_1982.htm

Congreso de la República. (1990, 28 de diciembre 28). Ley 54, Por la cual se definen las uniones maritales de hecho y régimen patrimonial entre compañeros permanentes.

Diario Oficial No. 39.615. Recuperado de https://www.icbf.gov.co/cargues/avance/ docs/ley_0054_1990.htm

Congreso de la República. (1992, 17 de diciembre). Ley 25, Por la cual se desarrollan los incisos 9, 10, 11, 12 y 13 del artículo 42 de la Constitución Política. Diario Oficial No. 40.693. Recuperado de ttp://www.secretariasenado.gov.co/senado/basedoc/ ley_0025_1992.html

Congreso de la República. (2005, 26 de Julio). Ley 979, Por medio de la cual se modifica parcialmente la Ley 54 de 1990 y se establecen unos mecanismos ágiles para demostrar la unión marital de hecho y sus efectos patrimoniales entre compañeros permanentes.

Diario Oficial No. 45.982. Recuperado de http://www.suin-juriscol.gov.co/ viewDocument.asp?ruta $=$ Leyes $/ 1672162$

Consejo nacional legislativo. (1887, 15 de agosto 15). Ley 153 Por la cual se adiciona y reforma los códigos nacionales, la ley 61 de 1886 y la 57 de 1887. Diarios Oficiales Nos. 7.151 y 7.152 , del 28 de agosto de 1887

Constitución Política de Colombia. (1991, 4 de julio). Gaceta Constitucional n. ${ }^{\circ} 116$. Recuperado de http://www.secretariasenado.gov.co/index.php/constitucionpolitica.

Corte Constitucional. (1994, 19 de mayo). Sentencia C-239. MP. Dr. Jorge Arango Mejía. Expediente D-445. Recuperado en https://www.corteconstitucional.gov.co/ relatoria/1994/C-239-94.htm

Corte Constitucional. (1996, 21 de marzo). Sentencia C-114. MP. Dr. Jorge Arango Mejía. Expediente D-934. Recuperado de https://www.corteconstitucional.gov.co/ relatoria/1996/C-114-96.htm

Corte Constitucional. (1996, 29 de abril). Sentencia C-174. MP. Dr. Jorge Arango Mejía. Expediente D-1047. Recuperado de https://www.corteconstitucional.gov.co/ relatoria/1996/C-174-96.htm 
Corte Constitucional. (1999, 7 de julio). Sentencia C-477. MP. Dr. Carlos Gaviria Díaz. Expediente D-2280. Recuperado de https://www.corteconstitucional.gov.co/ relatoria/1999/C-477-99.htm

Corte Constitucional. (2002, 27 de noviembre). Sentencia C-1033. Magistrado Ponente: Dr. Jaime Córdoba Triviño. Recuperado de https://www. corteconstitucional.gov.co/relatoria/2002/c-1033-02.htm\#: :text=Sentencia\%20 C\%2D1033\%2F02\&text=El\%20principio\%20de\%20la\%20justa,ser\%20 relevantes\%20para\%20el\%20derecho.

Corte Constitucional. (2003, 7 de octubre). Sentencia C-901. MP. Dr. Rodrigo Escobar Gil. Expediente D-4563. Recuperado de https://www.corteconstitucional.gov.co/ relatoria/2003/C-901-03.htm

Corte Constitucional. (2009, 28 de Enero).Sentencia C-029. MP. Dr. Rodrigo Escobar Gil. Expediente D-7290. Recuperado de https://www.corteconstitucional.gov.co/ relatoria/2009/c-029-09.htm

Corte Constitucional. (2011, 26 de julio). Sentencia C-577. MP. Dr. Gabriel Eduardo Espinoza Martelo. Expedientes acumulados D-8367 y D-8376. Recuperado de https://www.corteconstitucional.gov.co/relatoria/2011/C-577-11.htm

Corte Constitucional. (2015, 15 de noviembre). Sentencia C-727. MP. (E): Dra Myriam Avila Roldán. Expediente D-10806. Recuperado de https://www.corteconstitucional. gov.co/RELATORIA/2015/C-727-15.htm\#: :text=c.,sacrificio\%20de\%20su\%20 propia\%20existencia.

Corte Constitucional, Sala Plena. (2016, 28 de abril). Sentencia SU 214. MP. Dr Alberto Rojas Ríos. Expediente T- 4.167.863 AC. Recuperado de https://www. corteconstitucional.gov.co/relatoria/2016/su214-16.htm

Corte Suprema de Justicia, Sala de Casación Civil y Agraria. (2000, 20 de septiembre). Sentencia 6117. MP. Dr. Silvio Fernando Trejos Bueno. Recuperado de https://cortesuprema-justicia.vlex.com.co/vid/552515486

Corte Suprema de Justicia, Sala de Casación Civil. (2001, 12 de diciembre). Sentencia 6721. MP. Dr Jorge Santos Ballesteros. Recuperado de https://www.redjurista.com/ Documents/corte_suprema_de_justicia,_sala_de_casacion_civil_e._no._s-239-2001_ de_2001.aspx\#/

Corte Suprema de Justicia. Sala de Casación laboral. (2012, 12 de febrero). Radicación 36.764. MP. Dr. Rigoberto Echeverry Bueno. Recuperado de https://www.redjurista. com/Documents/corte_suprema_de_justicia,_sala_de_casacion_laboral_e. no._39206_de_2012.aspx\#/

Corte Suprema de Justicia, Sala de Casación Civil. (2013, 5 de agosto). Sentencia 200800084 Rad 2004-00084-02. MP. Dr. Fernando Giraldo Gutiérrez. Recuperado en cortesuprema.gov.co > SC4499-2015 (2008-00084-02)

Corte Suprema de Justicia. Sala de Casación Civil. (2016, 24 de octubre), SC151732016, Exp. 2011-00069-01. Radicación: 05001-31-10-008-2011-00069-01. MP. Luis Armando Tolosa Villabona. Recuperado de www.cortesuprema.gov.co > corte > relatorias > boct2016

Corte Suprema de Justicia. Sala de Casación Civil. (2018, 7 de febrero) SC4360-2018. Radicación n054*0013110005200900599-01. MP. Luis Armando Tolosa Villabona. Recuperado en https://cortesuprema.gov.co/corte/wp-content/uploads/2018/10/ SC4360-2018-2009-00599-01.pdf 
Presidencia de la República (1970, 27 de julio) Decreto 1260. Por el cual se expide el Estatuto del Registro del Estado Civil de las Personas. Diario Oficial No. 33.118. Recuperado de http://www.secretariasenado.gov.co/senado/basedoc/ decreto_1260_1970.html

Engels, F. (1980). El Origen de la familia, la propiedad privada y el estado. Caracas: Editores Mexicanos Unidos.

Escribano, M. V. (2008). Cristianos y Judíos: Separados por la ley (CTH III, 7,2=IX, 7,5. 388). (r. d. Paginas, Ed.) Retrieved Enero 21, 2021, from file:///C:/Users/senoritas/ Downloads/Dialnet-CristianosYJudios-5537585.pdf

Hubeñak, F. (1999). El hispano Teodosio y la cristianización del imperio. (n. 1. Hispania Sacra 51, Ed.) Retrieved from Biblioteca Digital de la Universidad Católica Argentina: http://bibliotecadigital.uca.edu.ar/repositorio/contribuciones/hispano-teodosiocristianizacion-imperio.pdf

Marín, M. D. (2005). Mujer y concubinato en la sociedad romana . (U. d. Murcia, Ed.) Anales de Derecho(23), 239-248.

Ocaña F., S. (2017, Octubre). (U. D. Postgrado, Ed.) Retrieved Enero 20, 2021, from Violencia, marginación, delitos sexuales y capacidad jurídica de la mujer en «LAS PARTIDAS»ALFONSÍES http://tauja.ujaen.es/bitstream/10953.1/6368/1/TFM\%20 Sergio\%200cana\%20Fernandez\%20\%28Violencia\%20y\%20marginacion\%20 Partidas\%20Alfonsies\%29.pdf

Secretaría de Cultura Gobierno de México. (2019, Octubre 21). Esclavitud de africanos y afrodescendientes en la Nueva España. Retrieved from https://www.gob.mx/ cultura/es/articulos/esclavitud-de-africanos-y-afrodescendientes-en-la-nuevaespana?idiom $=$ es

Tribunal Superior del Distrito Judicial de Medellín. (2019, 28 de mayo). MP. Dra. Ana María Zapata Pérez. Caso radicado: 050013105007 2015-01955 01 Recuperado de https:// tribunalmedellin.com/images/decisiones/laboral/050013105007201501955.pdf

Valencia, H. (1986). Derecho privado romano. Bogotá: Temis S.A.

Veiga, M. (2016). Matrimonio monogámico en la cultura occidental. Revista Tesis Psicológica, 11(2), 158-167. Retrieved Enero 21, 2021, from https://www.redalyc. org/pdf/1390/139053829009.pdf 